\title{
Sumon: Pemantauan Kualitas dan Volume Susu Segar Pada Cold Storage berbasis IoT
}

\author{
Teguh Sutanto ${ }^{1}$ Norma Ningsih ${ }^{2}$ Harianto $^{3}$ \\ ${ }^{1,2}$ Program Studi Sistem Informasi, Universitas Dinamika Surabaya \\ ${ }^{3}$ Program Studi Teknik Komputer, Universitas Dinamika Surabaya \\ Email: ${ }^{1}$ teguh@dinamika.ac.id, ${ }^{2}$ norma@dinamika.ac.id , ${ }^{3}$ hari@dinamika.ac.id
}

\begin{abstract}
Abstrak: Penyimpanan susu segar membutuhkan pengaturan dan pemantauan suhu yang optimal agar kualitas susu segar dapat dipertahankan. Kondisi saat ini cold storage hanya bisa menampilkan temperature susu saat ini, tetapi data histori temperature dan keasaman susu tidak terekam dengan baik. Informasi distribusi susu segar dari petani susu ke KUD penyimpanan susu kemudian ke Industri Pengolah Susu (IPS) butuh yang lama. Penelitian ini mengusulkan Perangkat IoT Master dan Slave yang dapat digunakan untuk menyelesaikan permasalahan penyimpanan, pemantauan dan pengendalian persedian susu segar. IoT Node terdiri dari sensor suhu ruang, suhu susu, $\mathrm{Ph}$ meter, dan ultrasonic. Data dari sensor akan diproseses oleh IoT Node untuk kemudian dikirim ke IoT Master Controller. IoT Master Controller akan mengirimkan data ke server cloud. Berdasarkan data tersebut maka kondisi susu dalam cold storage dapat dipantau kualitas dan ketersediaannya.
\end{abstract}

Kata Kunci: IoT, JSON, Ultrasonic, Ph meter, HttpConnection

\begin{abstract}
Fresh milk storage requires optimal temperature regulation and monitoring so that the quality of fresh milk can be maintained. The current condition of cold storage can only display milk temperature at this time, but historical temperature and acidity data of milk is not recorded properly. Information on the distribution of fresh milk from milk farmers to the KUD for milk storage and then to the Milk Processing Industry (IPS) takes a long time. This research proposes the IOT Master and Slave Tool that can be used to solve the problem of storage, monitoring and control of fresh milk supply. IOT Node consists of room temperature sensors, milk temperature, Ph meter, and ultrasonic. Data from the sensor will be processed by the IoT Node and then sent to the IoT Master Controller. IoT Master Controller will send data to the cloud server. Based on these data, the condition of milk in cold storage can be monitored for its quality and availability
\end{abstract}

Keywords: IOT, JSON, Ultrasonic, Ph meter, HttpConnection

\section{PENDAHULUAN}

Dewan persusuan nasional memperkirakan indonesia akan mengalami darurat susu segar dalam negeri pada tahun 2020 . Karena kemampuan produksi susu segar dalam negeri diprediksi hanya mampu memenuhi sepuluh persen dari kebutuhan nasional. Pada saat ini produksi susu segar dalam negeri hanya memenuhi 18 persen dari total kebutuhan nasional 4,45 juta ton per tahun, sisanya sebanyak 82 persen kebutuhan susu nasional dipenuhi dengan impor.

Model distribusi susu segar dari peternak (petani susu) ke industri pengolah susu (IPS) melalui jalur yang cukup panjang [1]. Jalur distribusi dimulai dari peternak kemudian disetorkan ke KUD susu setelah memenuhi jumlahnya baru disetorkan ke IPS. Karena jarak antara Koperasi Unit Desa (KUD) ke IPS cukup jauh sehingga untuk proses pengiriman susu harus menunggu cukup banyak maka diperlukan proses penyimpanan. Untuk menyimpan susu supaya tahan lama diperlukan tempat penyimpanan dengan suhu kurang dari $3^{\circ} \mathrm{C}$ yang juga dinamakan cooling unit. Terjadinya kesalahan penyimpanan dapat mengakibatkan berkurangnya ketahanan susu yang mempengaruhi kualitas susu [2] [3]. Kendala yang dialami oleh IPS saat ini adalah tidak bisa mengamati secara langsung suhu dalam mesin cooling unit yang tersebar pada 
KUD yang jaraknya cukup jauh. Selain itu industri pengolah susu juga tidak bisa melihat secara langsung banyaknya susu yang sudah tersimpan dalam cooling unit sehingga sulit untuk melakukan manajemen perencanaan produksi yang berhubungan dengan banyaknya bahan baku yang tersedia. Dalam masa industri 4.0 saat ini permasalahan tersebut dapat diselesaikan dengan menggunakan teknologi Internet of Thing (IoT). Saat ini IoT sudah mulai diimplementasikan dalam bidang pertanian, dan peternakan [4]. Mesin Cooling unit (Cold Storage) yang terdapat pada KUD yang tersebar pada jarak yang cukup jauh dari IPS diberikan sensor ultrasonic yang digunakan untuk mengukur volume susu [4] dan sensor suhu yang berfungsi untuk mengukur suhu susu dan sensor $\mathrm{Ph}$ untuk mengukur tingkat keasaman susu yang ada dalam mesin cooling unit [5]. Dengan implemetaasi IOT maka data suhu dan jumlah susu yang ada di cooling unit KUD dapat dikirim ke IPS dan selanjutnya diolah untuk manejemen pengaturan bahan baku.

\section{METODE}

\section{Internet of Things (IOT)}

Sebuah system dapat dikategorikan sebagai Internet of Things jika memilki 4 komponen [7], yaitu:

1. Alat dengan fungsi tertentu

2. Kontroler, sensor dan actuator

3. Jalur koneksi dengan internet

4. IoT Broker and Management

\section{JSON}

JSON (JavaScript Object Notation) adalah sebuah format pertukaran data yang ringan [6]. Format data JSON sangat mudah untuk dibaca dan ditulis oleh manusia. JSON menggunakan format text yang tidak terikat oleh sebuah Bahasa pemrograman tertentu. JSON digunakan dalam penelitian ini karena diharapkan dapat mengirimkan data-data sensor ke server cloud dengan lebih ringan dan cepat. struktur:

JSON dibangun dengan dua format

1. Koleksi dari pasangan nama dan nilai. Pada beberapa Bahasa pemrograman koleksi ini diimplementasikan dalam bentuk object, record dan hashmap.

2. Array, kumpulan nilai yang terurut yang terdiri dari index array dan nilai array.
Seperti terlihat pada Gambar 1 adalah sebuah JSON dengan struktur objek yang diawali dengan "\{“ dan diakhiri dengan " $\}$ ". Di dalam koleksi objek terdapat pasangan nama (sebagai key) dan nilai (sebagai data yang tersimpan dalam objek yang diacu oleh key).

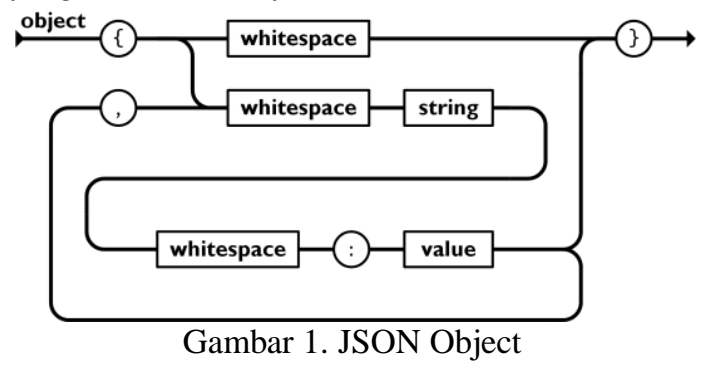

\section{Analisis System}

Berdasarkan analisa kebutuhan system maka alur distribusi yang diusulkan dalam penelitan ini dapat dilihat pada Gambar 2. Alur distribusi melibatkan aktor Peternak, KUD dan IPS.

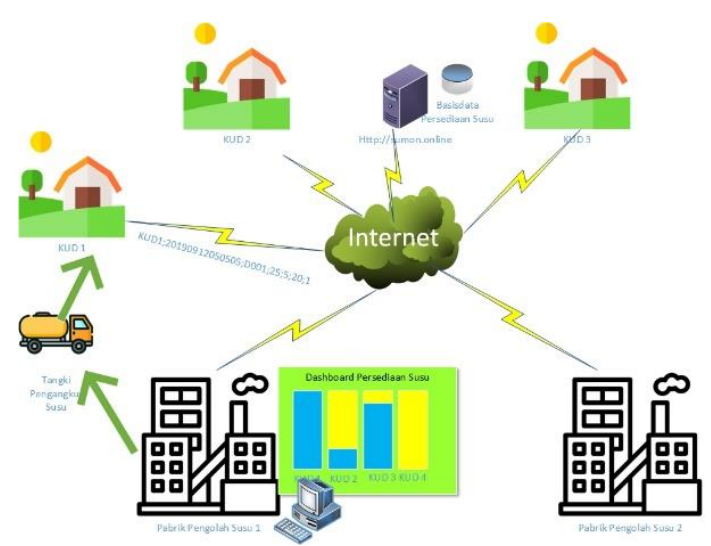

Gambar 2. Alur Distribusi Susu dan Informasi

Peternak membawa susu segar ke KUD, kemudian

\section{Arsitektur}

Berdasarkan Alur distribusi tersebut maka rancangan arsitektur IOT yang diusulkan dapat dilihat pada Gambar 3 . Arsitektur terdiri dari:

1. Things adalah objek yang diamati yang digunakan sebagai sumber data.

2. Sensors dan Actuator

3. Internet Gateways dan Data Aquitition

4. Edge IT 
5. Data Center

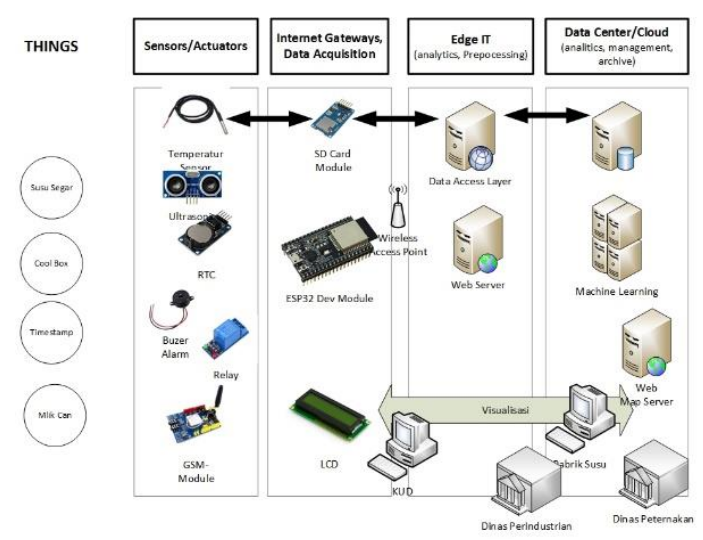

Gambar 3. Arsitektur IOT Sumon

\section{Rancangan Perangkat IOT}

Rancangan perangkat IOT dalam penelitian ini terdiri dari dua perangkat utama yaitu: IOT Master dan IOT Node (lihat ). IOT Master berfungsi sebagai Internet Gateway dan Data Aquitition. Sedangkan IOT Node berfungsi sebagai pengumpul data sensor yang akan diletakkan dakan cold storage.

Dengan rancangan perangkat IOT seperti Gambar 4 memungkinkan diimplementasikan ke KUD atau Tempat Penyimpanan Susu segar yang memiliki lebih dari satu cold storage.

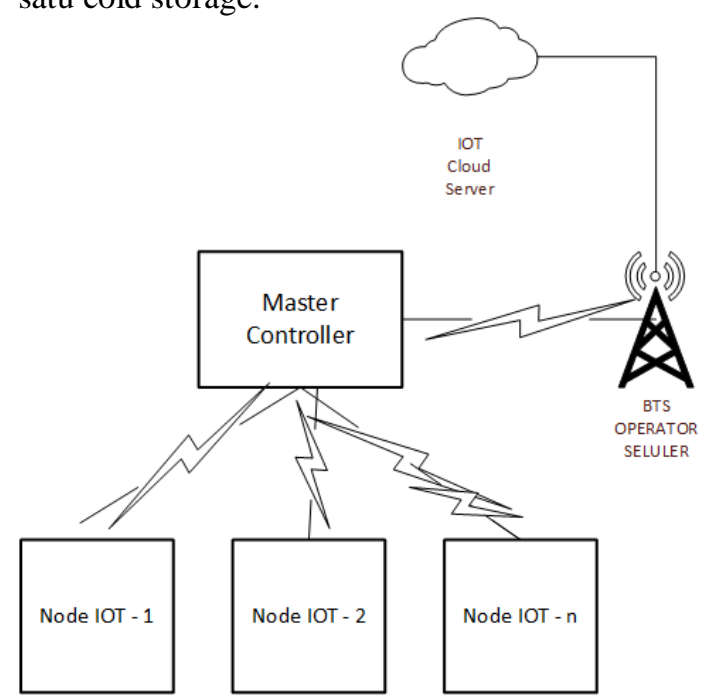

Gambar 4. Rancangan Umum Perangkat IOT

Master Controller akan membuka layanan Socket Server yang akan menerima IOT Node yang melakukan koneksi menggunakan SocketClient melalui WiFi.

\section{Master Controller}

Master controller (IoT-MC) adalah perangkat IoT yang berfungsi untuk menerima data-data dari sensor yang dikirimkan oleh IoT Node, menyimpan data sensor ke dalam SC Card, mengirimkan data sensor ke server cloud melalui koneksi yang disediakan oleh modul GSM. Komponen utama IoT-MC (Gambar 6):

1. Board ESP32 Dev Kit

2. Buzzer

3. Module GSM (SIM9000A)

4. SD Card Reader

5. RTC

Rancangan program IoT Master Controller dapat dilihat pada Gambar 5.

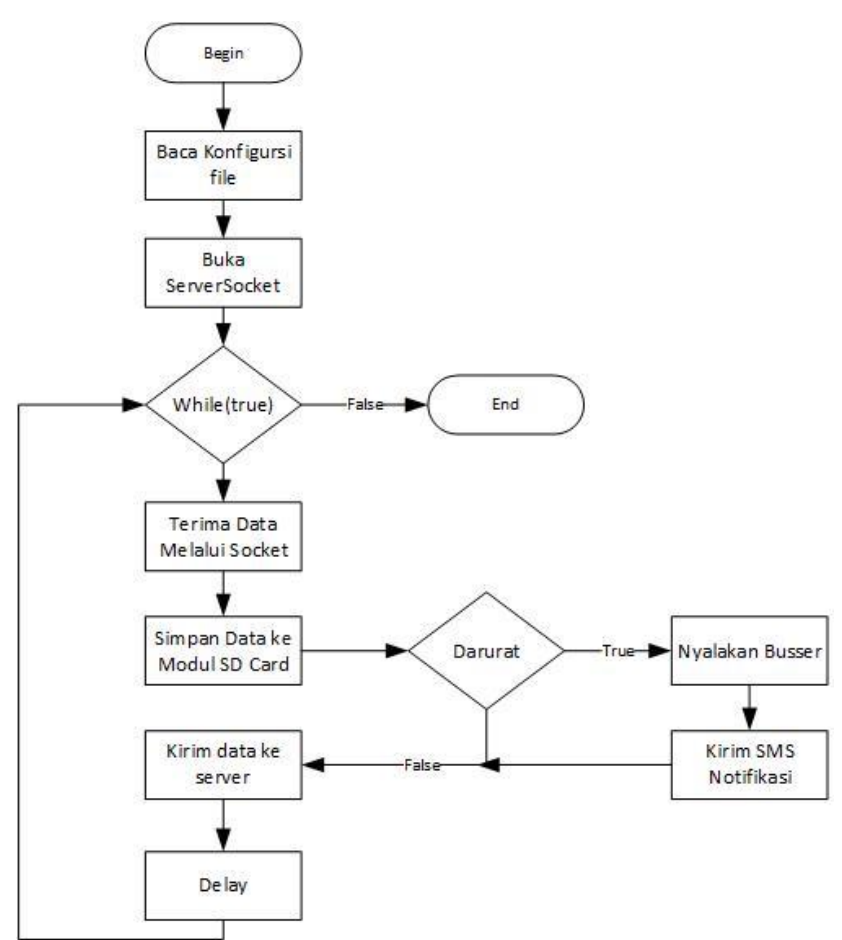

Gambar 5. Flowchart IOT Master Controller 


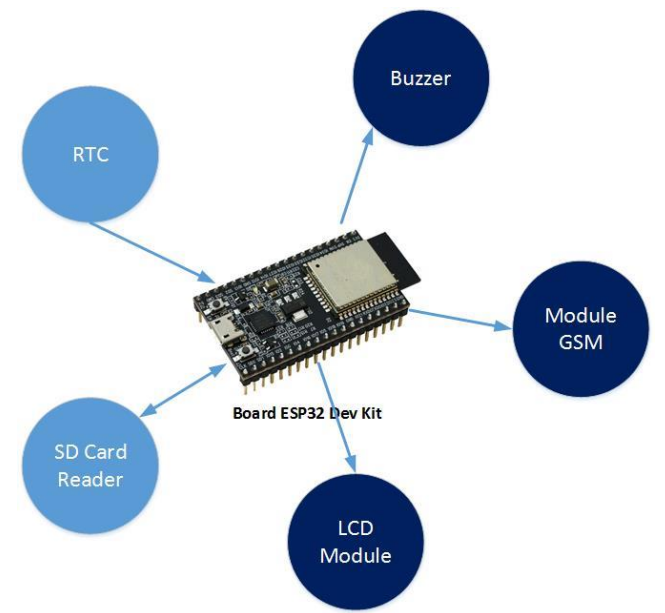

Gambar 6 Perangkat IoT Master Controller

\section{Node IoT}

IOT Node adalah perangkat IoT yang berfungsi untuk membaca sensor-sensor yang terhubung, mengubah besaran nilai sensor kemudian mengirimkan ke IoT Master Controller.

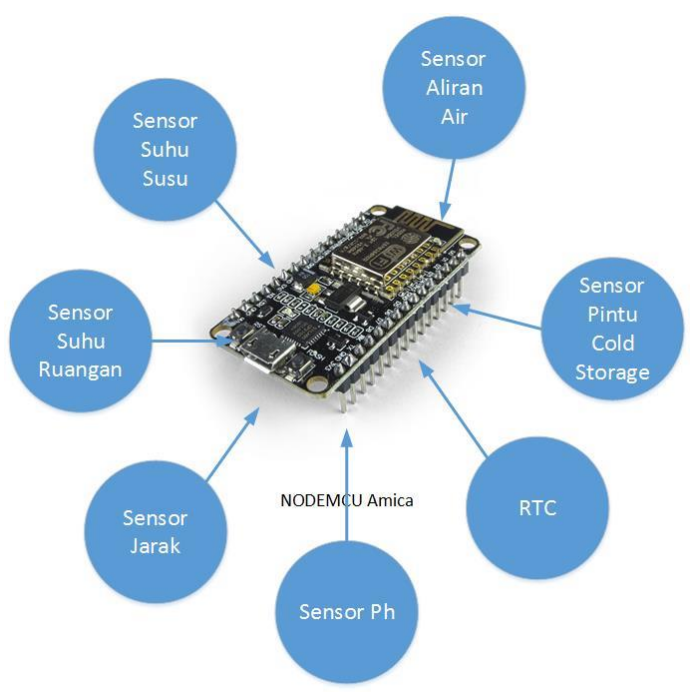

Gambar 7. Perangkat IoT - Node Sensor

Seperti padaGambar 7, IoT Node terdiri dari komponen sebagai berikut:

1. Board Node MCU Amica

2. Sensor Suhu
a. Sensor Suhu Ruangan
b. Sensor Susu Susu

3. Sensor Jarak

4. Sensor $\mathrm{Ph}$

5. Sensor Aliran Air

6. Sensor Pintu

7. RTC
Rancangan program pada IOT Node dapat dilihat pada Gambar 8. Program diawali dengan membuka Socket Client supaya bisa terhubung dengan IOT Master Controller.

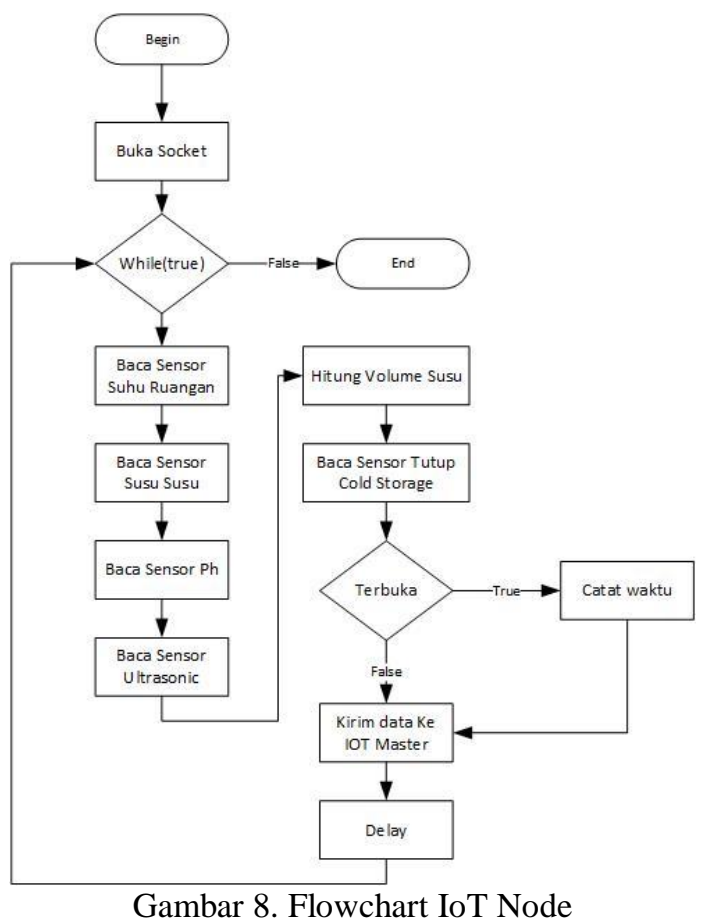

\section{HASIL DAN PEMBAHASAN}

Berdasarkan rancangan di atas maka, langkah berikutnya adalah implementasi dalam bentuk perangkat keras IoT dan perangkat lunak yang akan dijalankan di server cloud. Seperti terlihat pada Gambar 9 adalah perangkat IoT Master Controller yang dihasilkan oleh penelitian ini.

Sebelum dijalankan IoT Master Controller perlu dilakukan pengaturan parameter seperti pada Tabel 1. Setting parameter disimpan dalam format file text dengan nama setenvir.txt dalam SD Card.

Tabel 1. Parameter Pengaturan IoT Master Controller

\begin{tabular}{|l|l|l|}
\hline Parameter & \multicolumn{1}{|c|}{ Keterangan } & \multicolumn{1}{c|}{ Contoh } \\
\hline IPServer & $\begin{array}{l}\text { Alamat IP dari } \\
\text { Server Cloud }\end{array}$ & 2 \\
\hline Port Server & $\begin{array}{l}\text { Port yang } \\
\text { digunakan } \\
\text { Server Cloud }\end{array}$ & Port:8080 \\
\hline
\end{tabular}




\begin{tabular}{|c|c|c|}
\hline Parameter & Keterangan & Contoh \\
\hline & $\begin{array}{l}\text { untuk membuka } \\
\text { layanan }\end{array}$ & \\
\hline User & $\begin{array}{l}\text { Nama user } \\
\text { untuk konek ke } \\
\text { server }\end{array}$ & User:admin \\
\hline Password & $\begin{array}{l}\text { Password untuk } \\
\text { user }\end{array}$ & Pass:admin 1234 \\
\hline NoDarurat & $\begin{array}{l}\text { Nomor telpon } \\
\text { yang akan } \\
\text { dikirim SMS } \\
\text { jika ada indikasi } \\
\text { pengeluaran } \\
\text { susu ilegal }\end{array}$ & $\begin{array}{l}\text { Nodar:0856307 } \\
6813\end{array}$ \\
\hline interval & $\begin{array}{l}\text { Durasi dalam } \\
\text { satuan detik } \\
\text { yang } \\
\text { menentukan } \\
\text { setiap berapa } \\
\text { detik akan } \\
\text { mengirim data } \\
\text { ke server cloud }\end{array}$ & Durasi:5 \\
\hline
\end{tabular}

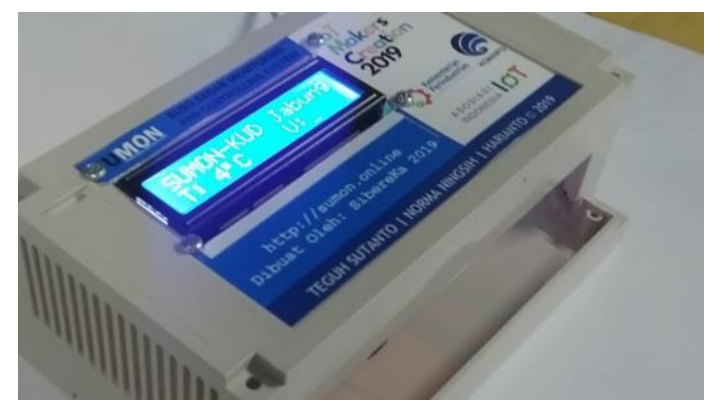

Gambar 9. Produk IoT Master Controller Sumon

\section{Pengujian Pengiriman Data}

Pengiriman data dari IoT Master controller ke server cloud menggunakan format JSON seperti pada:

\section{KESIMPULAN}

Penelitian ini telah menghasilkan rancangan dan perangkat IoT yang dapat digunakan untuk memantau kondisi susu segar yang tersimpan dalam cold storage.

\section{SARAN}

Saran untuk penelitian berikutnya adalah:

1. Pengembangan aplikasi di sisi server cloud

2. Pembuatan dashboard untuk pengelola KUD dan Manajemen Industri Pengolah Susu
3. Integrasi sistema dengan dinas terkait (Peternakan dan Industri).

\section{DAFTAR PUSTAKA}

[1] D. A. Sutrisno, S. Kumalaningsih and A. F. Mulyadi, "Study of Fresh Milk Stability in Transport with Low Temperature that Technically and Financially Feasible (Study on Temperature and Cooling Time)," Jurnal Teknologi Pertanian, vol. Vol. 16 No. 3, pp. 207-212, 2015.

[2] L. A. Nababan, I. K. Suada and I. B. N. Swacita, "The Endurance Of Fresh Milk At Room Temperature Storage Viewed By Acidity Level Test (Ph), Boiling, And Time Reductase)," Indonesia Medicus Veterinus 3(4) :, vol. 3(4), pp. 274-282, 2014.

[3] H. RESNAWATI, "Kualitas Susu Pada Berbagai Pengolahan," in Semiloka Nasional Prospek Industri Sapi Perah Menuju Perdagangan Bebas, 2020.

[4] D. Kurniawan, Y. and G. Suprayitno, "Implementasi Internet of Things pada Sistem Irigasi Tetes dalam Membantu Pemanfaatan Urban Farming," in The 7th University Research Colloquium, Surakarta, 2018.

[5] Sumardi, "Implementasi Sensor Level Untuk Alat Ukur Volume Cairan Serba Guna Di Lingkungan Industri," TRANSMISI, Jurnal Teknik Elektro, Vols. Volume 11, Nomor 2, pp. 91-99, 2009.

[6] E. Wahyupradipta and M. Taufiqurrohman, "Rancang Bangun Alat Uji Kualitas Air Susu Sapi Berbasis Arduino Menggunakan Metode Fuzzy Logic," in Seminar Nasional Kelautan XIII , Surabaya, 2018.

[7] H. Santoso, Monster Arduino 3 Implementasi Internet Of Things pada Jaringan GPRS, Malang: ElangSakti, 2018.

[8] T. Sutanto, N. Ningsih and H. Harianto, "Kolaborasi Buku Catatan Digital pada Perangkat Android berbasis Distributed Client Server," Jurnal Ilmial Scroll, vol. Vol.7 No.1, pp. 33-41, 2019. 